\title{
Three Neofunctionalist Conceptual Contributions to the Institutional Theory in Organizations ${ }^{(1)}$
}

\author{
João Marcelo Crubellate* \\ E-mail address: jmcrubellate@terra.com.br \\ PPA-UEM/UEL \\ Maringá, PR, Brazil
}

\begin{abstract}
The most recent efforts in institutional theory applied to organization studies search for ways to overcome consequences of traditional dichotomies based on levels of analysis, social structures versus agency as source of practices, and so on. If in other social sciences that debate has received fundamental contributions in the last three or four decades, this is not the case for Organization Theory, where discussions are much more recent and based especially on Sociology authors. The main purpose of this theoretical essay is to describe some neofunctionalist concepts - system openness and closeness, double contingency and expectation of expectations - proposed by Niklas Luhmann, discussing their impact on those dichotomies, in the realm of the Luhmannian theory of institutions. This effort is expected to contribute alternatives to that theoretical discussion that mark institutional organization theory for at least the past two decades.
\end{abstract}

Key words: institutional theory; Luhmann; neofunctionalism; organizations.

Received 21 February 2006; received in revised form 30 May 2006.

Copyright (C) 2007 Brazilian Administration Review. All rights reserved, including rights for translation. Parts of this work may be quoted without prior knowledge on the condition that the source is identified.

* Corresponding author: João Marcelo Crubellate

Rua Ana Cordeiro Dias, 368, Maringá/PR, 87023-100, Brazil. 


\section{INTRODUCTION}

The relationship between organizations and institutions lies at the heart of organizational studies. This indicates an important basic conflict as a framework of discussions surrounding the phenomenon of organizations, i.e. the discussion concerning the bases of social action, with rationalist and contingency explanations as the predominant alternatives. In this sense, the Theory of Organizations appears to be characterized, from the first, by the counter position to rationalism of the economic theories concerning human behavior, as seen in the studies of Simon (1970) and Selznick (1957, 1966). In addition, the institutional theory in organizations has always been a promising alternative.

According to Scott (2001) even the institutionalist perspective in the Economy arose as opposition to thinking based on the presupposition of rational and individualized economic behavior. Meanwhile, in Sociology, two classic perspectives in the treatment of the institutional phenomenon have marked the evolution of discussions into that theme and, even today, organizational theory. These perspectives are: the functionalist notion of environmental determination, from which institutions were defined as social facts by which autonomy and free will were seriously affected; and the interpretativist notion which, while not denying the importance of social conditioners, it reserved space for autonomy in the process of meaning, a necessary element for all action. The later development of the institutional analysis has become guided by some opposition and dichotomies and these were, as a result, also brought into the scope of organizational analysis.

More recently, the efforts in institutional theory in organizations has been towards seeking to overcome traditional dichotomies in social and organizational theories, dichotomies concerning analysis levels or the relationship between structures and action as sources of social practices. In the scope of social theory, for some time analysis perspectives of social reality have been built which point out pathways to overcome these dichotomies. In the organization theory, these much more recent attempts have been made mostly by the appropriation of concepts and theories from other areas, mainly Sociology.

In this article, we propose to describe these concepts of theory of autopoietic social systems in the framework developed by Niklas Luhmann and, based on these concepts, analyze the alternative possibilities for institutional theories in organizations, in which a reference is made to some of the theoretical debates which have taken place concerning that perspective for at least two decades. For Luhmann, the question of institutionalization is shown to be central to the explanation of processes of conforming to social and organizational reality. But unlike other authors who also admit this centrality, Luhmann remains little explored in organizational theory. The intention here is to contribute towards filling this gap and, furthermore, point out the potential of the neofunctionalist perspective in the analysis of organizational and administrative issues, a perspective that may acquire greater relevance as the contemporary 'society of organizations' becomes increasingly more complex.

\section{LACK OF DeFINITIONS AND CONFLICTS In INSTITUTIONALIST ORGANIZATIONAL THEORY}

A purely rationalist approach of action is based mainly on the presupposition that all action follows a logic of maximization of self interest (Boudon, 1998). This notion, as pointed out by Granovetter (1985, p. 483), is central to Classical and Neoclassical Economics, its basis lying in "[...] an atomized, undersocialized conception of human action”. This mode of action is understood as a product of subjects in search of maximization of their own interest, "[...] affected minimally by social relations" (Granovetter, 1985, p. 481). The most radical form of this perspective admits that the environmental context that surrounds social actors (individuals or organizations) is a product of the competition between those actors and so the circumstances of social atomization are understood as a logical premise for perfect competition. 
In parallel with this version, there developed in Sociology "[...] a conception of people as overwhelmingly sensitive to the opinions of others and hence obedient to the dictates of consensually developed systems of norms and values, internalized through socialization [...]” (Granovetter, 1985, p. 483). This normativist conception of social action, formulated by Parsons (1951), was so important for social and organizational theory that it received varied and differing criticisms. Its influence is evident from the earliest stages of the theory of organizations and until today, even though the same extremism is not repeated of the normativist conception of action. In the theory of organizations, the question seems to have remained in terms of the tendency to emphasize aspects that are external to the organizations - within them the institutions - as independent variables in relation to the social systems, mainly with the rise of the notion of open systems as an analytical paradigm.

In this perspective, the seventies will be constituted as groundbreaking in organizational theory by the impulse of the movement which became known as 'new institutionalism' with its cognitivist emphasis of explanation of the fundamentals of social action (DiMaggio \& Powell, 1983; Meyer \& Rowan, 1977; Zucker, 1977). Despite this new emphasis, the new institutionalism remains in the contingency tradition of locating in the environment the conditioning elements of action. As stated by DiMaggio and Powell:

The new institutionalism in organization theory and sociology comprises a rejection of rational-actor models, an interest in institutions as independent variables, a turn toward cognitive and cultural explanations, and an interest in properties of supraindividual units of analysis that cannot be reduced to aggregations or direct consequences of individuals' attributes or motives (DiMaggio \& Powell, 1991, p. 8, emphasis added).

Here there are at least three important debates that have become the guides for institutional theory in organizations in recent years.

The first of these debates follows sociological traditions by positioning itself against the paradigm of rational choice. What is predominant in the institutional theory in organizations is the understanding that the capacity for rational decision making of systems is affected by the contingencies of their context (DiMaggio \& Powell, 1991; Machado-da-Silva \& Fonseca, 1999; Meyer \& Rowan, 1977). To Machado-da-Silva and Fonseca (1999, p. 31), "according to the institutionalists, organizations are inserted in an environment that is constituted by rules, beliefs and values, created and consolidated through social interaction. In this sense, their survival depends on the capacity to follow collectively shared guidelines [...]". This is one of the central understanding in the institutional perspective, generally accepted explicitly or implicitly under the concept of institutional environment (DiMaggio \& Powell, 1983; Machado-da-Silva \& Fonseca, 1999; Meyer \& Rowan, 1977; Scott \& Meyer, 1994; Tolbert, 1985). In this perspective of understanding, however, the institutional environment is defined as determining organizational behavior or, at least, as an independent variable in relation to it.

In an even more radical way, Zucker (1991, p. 83) focuses only on the structuring aspect of environments when she admits that "[...] social knowledge once institutionalized exists as a fact, as part of objective reality, and can be transmitted directly on that basis" (Zucker, 1991, p. 83). This conception, whose fundaments are recognizably linked to Durkheimian sociology, tends to equate an elevated degree of institutionalization with direct reproduction of the social pattern, resistance to its change (Zucker, 1991) and the constitution of habits of behavior (Tolbert \& Zucker, 1996). According to DiMaggio and Powell (1991, p. 11), "institutionalized arrangements are reproduced because individuals often cannot even conceive of appropriate alternatives (or because they regard as unrealistic the alternatives they can imagine)". Understood thus, the institutional environment has an elevated strength for diffusing social patterns of knowledge similar to the power of diffusion of normative patterns in the conception of Parsons (1951). Apparently, some studies (Zucker, 1991; Tolbert \& Zucker, 1983) substituted normative supersocialization for a sort of 'cognitive supersocialization', following the guidelines that institutionalized patterns determine action by determining the form of perceiving and interpreting reality. Thus, organizational actions are understood as necessarily connected in a high degree to institutionalized patterns (Tolbert \& Zucker, 1996). 
To Lourau (1995) this perspective of understanding the institutional order only as an instituted order' (not considering the counterpoint that is inherent to the concept, i.e. the role of instituting agents, in the concept of that author) is constituted as one of the sociological errors developed in the study of the matter and in relation to which is proposed, in his study, to counter position returning to "the concept of institution its dynamic significance" (Lourau, 1995, p. 136). According to him

To empty the concept of institution of one of its primitive instances (instituting in the sense of founding, creating, breaking with an ancient order and creating a new one), sociology ended up identifying institution with the established order. It is not by accident if at the moment in which order appears to social instituting layers as uniquely repressive, the word institution appears to designate only that which is instituted. This theoretical error, which revolutionaries frequently commit, has the sociology of the last fifty years to blame for it (Lourau, 1995, p. 136).

Likewise, Oliver (1991) highlights the fact that this emphasis on structuring character of the environment, seen as part of the theory of organizations it inherited from contemporary sociology, hampered the analysis of capacity for strategic action of social actors in the studies of some of the representatives of the institutional theory. In parallel, to this quasi-supersocialized conception, of agents and systems, several other writers have analyzed the influence of institutions without denying any degree of autonomy for them. There now arise the notions of organizational structure as simultaneously structuring of and structured by the actions of organizational actors (Ranson, Hinings, \& Greenwood, 1980) and embeddedness of action in opposition to its determination and its absolute freedom (Granovetter, 1985), in addition to the notion of institution as containing within itself instituted forces as instituting as outlined above based on Lourau (1995).

Granovetter (1985) is another author who criticizes strict opposition between the social and the individual. According to him, the conceptions of under and super socialized action is equal to his presupposition of atomization: the understanding that individual actions are determined by normative environment structures are the idea that the internalization of social values is given in such a profound way that individuals act as if these values were there own, i.e. without any awareness of their social origins (this also seems to be valued for the more radical versions of the new cogntivist institutionalism). The challenge, then, is to define the process by which institutions affect action without succumbing to one or another atomist version of action. Several authors in the field of organizational theory have proposed answers to this challenge, especially because it represents limitation of the organizational theory by suggesting that institutional and strategic approaches in organizations are mutually exclusive (Barley \& Tolbert, 1997; Machado-da-Silva, Fonseca, \& Crubellate, 2005; Oliver, 1991, but also Meyer \& Rowan, 1977; Scott, 1994, 1995; Westphal \& Zajac, 2001).

Perhaps the best way to describe the dichotomy that has at times been identified in institutional theory, as mentioned above, is to say that it is based on a still latent conflict in institutional theory in organizations concerning the nature of actors and social systems and their relationship with their environments. This conflict is present in the notion of closed and rational systems, constituents of their environments versus the notion of open systems constituted by their environmental contexts. Several recent efforts to overcome this dichotomy in social theory and institutional theory in organizations, as seen above, have not diminished the importance of other and different alternatives to analyze this conflict.

A second debate involved the supposed emphases that are predominant in institutional theory in organizations. To DiMaggio and Powell (1991, p. 15) one of the fundamental distinctions between the so-called old and new institutionalisms is that in the latter, it is understood that "not norms and values but taken-for-granted scripts, rules, and classifications are the stuff of which institutions are made". Zucker echoes this statement (as cited in DiMaggio \& Powell, 1991, p. 15) saying that "institutionalization is fundamentally a cognitive process".

To Selznick (1996, p. 274) the supposed cognitivist emphasis as a brand of the new institutionalism is not as innovative as it seemed to be at first because it corresponds to the interpretativist notion that 
"[...] the interaction of culture and organization is mediated by socially constructed mind, that is, by patterns of perception and evaluation”. Perhaps owing to the declared Weberian basis (evident in the argument of Selznick), the author that most seems to have moved towards the integration of several notions of the phenomenon of institutions is Scott (1994, 1995, 2001), to whom these institutions involve systems of meaning that "[...] must incorporate representational, constitutive, and normative rules" (Scott, 1994, p. 60) or, "cognitive, normative, and regulative structures and activities that provide stability and meaning to social behavior” (Scott, 1995, p. xiii).

But despite its integrative scope, the model of Scott $(1995,2001)$ continues to maintain institutional elements as conceptually segmented structures without sufficiently clear insight of their integration into the real plane, which seems to be indicative of space for attempts to explore this conflict in institutional theory that rests on the very definition of which this social phenomenon consists of or what exactly is its substance and concrete dynamic.

The third conflict mentioned above concerns the social level of occurrence of the institutionalization process. To DiMaggio and Powell (1991, p. 15) “[...] institutions are macro level abstractions”. But as Scott (2001) points out, this emphasis on the macro-social level as a locus in the process is not exclusive to the most recent institutional theory. According to him, "while Meyer and Rowan developed the macro side of the [institutional] argument, Zucker [...] emphasized the micro foundations of institutions” (Scott, 2001, p. 43).

To Zucker (1991) the predominance of institutional analyses at the macro-social level results from the focus on the content of institutions. She, in her turn, indicates that the analytical focus at the microsocial level predominant in studies results from greater concern over the institutionalization process, which is in other ways misunderstood. Also important is her suggestion that institutional studies with a macro-analytical focus should adopt as a research goal not the process but rather the effects of institutionalization, not allowing it to be perceived that "[...] institutionalization is a continuous rather than a binary variable" (Zucker, 1991, p. 104). To Zucker institutionalization always occurs on the local plane or even the individual plane, denying the possibility of individual resistance to highly institutionalized (in the sense of the operational decoupling supposed by Meyer and Rowan, 1977). This form of understanding institutions also excludes the possibility of different social planes in which the process of institutionalization may take place, by admitting only interpersonal relationships (micro plane) as a locus of institutionalization.

However that may be, there is here a conflict in the institutional theory in organizations concerning the social plane that is most suitable for the analysis of institutionalization processes and one of its important consequences is the definition of the possible effects of this process, with a reflex on the coherence or not of the supposition that some individual autonomy space (and strategic action) of highly institutionalized patterns, a question raised above.

We notice, however, that these oppositions are peculiar (or so they still remain) to the institutional studies in the theory of organizations. Outside of this scope, this dichotomy vision is already considered by some authors as in the process of being overcome. So it is that Lourau (1995), for instance, in his institutional analysis discusses some of the questions considered here of the perspective of a supposed opposition between privacy and universality. According to him:

It is common to confuse particularity and singularity, artificially opposing the general (or universal) with the particular, forgetting that this opposition is purely abstract and that there is no practice but only in idealist ideology and philosophy. (...) With the opposition of the particular to the general, the dialectic gives way to 'rational', 'natural' or 'fatal' antonyms between the individual and society (or 'the world'), antonyms that are resolved or by preponderance conceded to society or by preeminence attributed to the individual (Lourau, 1995, p. 10).

It seems evident that part of the institutional theory in organizations has still not overcome the stage of rational or natural oppositions between the categories of objectivity and subjectivity, organization and environment, individual and society, among others. Possibilities to advance in the sense of 
solution of these other conflicts seem to be contained in the theory of social systems and it is this expectation that we intend to witness below.

\section{THREE CONCEPTS IN NEOFUNCTIONALIST THEORY}

In Niklas Luhmann (1983; 1989; 1995) neofunctionalism has its main expression, constituting radicalization of functionalism: "[...] Luhmann gathers conditions to invert the Parsonian structuralfunctional viewpoint by changing the question from which functions are required by the system to how this is taken to respond to functional demands, i.e. functional operations” (Cohn, 1998, p. 58). The same author also states that

From the moment in which it suits the system to respond to functional demands and these demands derive from relations with an environment marked by contingency (incapable, therefore, of guiding the more adequate constitution of the system), there is now a new task to be faced: that of crating on its own its own elements and carrying out self constituting operations [...] (Cohn, 1995, p. 58).

Besides the notion of auotpoiesis, other neofunctionalist notions are found in this description, such as the ideas of complexity and differentiation and the very definition of social systems as simultaneously open and closed systems, which are discussed below as it is a fundamental notion for the purposes of this essay.

\section{Social Systems as Open and Closed Systems}

For the conventional systemic theory (Bertallanfy, 1975; Katz \& Kahn, 1976) the systems must be analyzed as having as a base the supposed fundamental distinction of their opening (in the case of permeable systems) versus closed (in the case of isolated systems) in relation to the environmental context, not admitting in general the logical or conceptual validity of intermediate definitions.

But for Luhmann (1989) the autopoietic nature of social systems demands understanding them as simultaneously open and closed systems. He also holds that they are sets of elements in interaction, including those interactions which, in their turn, constitute the basic mechanism from which systems conform to themselves in ongoing differentiation in relation to the environment, as they self reproduce. Luhmann follows the definition of Humberto Maturana and also understands systems as being autopoietically constituted, which means that the consist of "networks of productions of components that recursively, through their interactions, generate and realize the network that produces them" (Maturana as cited in Knodt, 1995, p. xx). In this definitions of systems the definition of autopoiesis is also implicit, i.e., the process by which living systems constitute themselves in a closed manner on themselves or, organizationally closed and that is in the basis of their own conservation. It may be dispensable, but it seems suitable to point out that, in this way, systems are more than the mere mechanical joining of their parts: in the conception of Luhmann, it is the process of autopoiesis that provides systems with their dynamicity and organicity.

Luhmann $(1989,1995)$ applies this idea to social systems (economy, politics, religion, art, education, organizations and society itself). To him, a social system "[...] comes into being whenever an autopoietic connection of communications occurs and distinguishes itself against an environment by restricting the appropriate communications” (Luhmann, 1989, p. 145). A social system has, therefore, as a central point of its nature, the capacity to process meanings and their communication, through which they self reproduce. Social systems differ from one another through the specific codification of each system, which, in its turn, constitutes its organizational kernel through which "[...] a system can change structures without losing its code-determined identity" (Luhmann, 1989, p. 45). Therefore, "[...] a system acquires the possibility of operating as closed and open simultaneously" (p. 45 - italics in the original), i.e., as a system that incorporates into its structure the pressures of the environmental context without being diluted into the environment, without altering its organization. 
Social systems, then, are autopoietic systems, which means that they are operationally closed. This does not imply, in turn, that they cannot be affected in any way by the environment. It does meant hat such systems are blind as to what happens beyond its boundaries, or in other words, they cannot receive information directly from or react directly to the environment. As an autonomous unit, any social system "[...] can react to its environment only in accordance with its own mode of operation, the mode of operation peculiar to it” (Bednarz Jr., 1989, p. xiii).

This peculiar mode of operation is based, in the social systems, in the process of meaning. Thus, information found in the environment will not flow directly across boundaries of the system to which they will be something like an annoyance (Luhmann, 2002) which triggers the process of meaning which is, as anticipated earlier in this essay, through the definition of system, internal and always self referring: "Meaning always refers to meaning [...]. Systems bound to meaning can therefore never experience or act in a manner that is free from meaning" (Luhmann, 1995, p. 62). As a consequence, "in principle, everything is accessible to meaning systems, but only in the form of meaning" (Luhmann, 1995, p. 63).

In short, social systems are structurally adaptable or open because they are, at the same time and necessarily, operationally or organizationally closed. They communicate in some way with their environment only as they themselves, produce or select internally the meanings to which they will respond and which will be utilized to configure and reconfigure the frontiers between system and environment (Luhmann, 1989, 1995; Paterson, 1997). This implies that the system itself self-produces and also produces its own environment, because it is the one to define its frontiers.

Such matters also result in implications for the notion of contingency relationship between systems and environments, which will be discussed below.

\section{Systems and Environments: Double Contingency}

The second neofunctionalist concept that we intend to discuss here derives from the conclusions presented above. When it is concluded that social systems are open and closed, it becomes possible to review the traditional idea of contingency. Conventionally, we take the relationship of contingency as one directional, which means that we admit that only environments affect systems or, in other words, that only the systems deal with the risk inherent to choices and the possibility of disappointment with the several options offered by the environment. According to Luhmann (1976, p. 96), "it has become customary to explain organizations by some kind of 'contingency theory' [...]. This means that differences in the structure of organizations can be explained by differences in their environment". Fundamental to this perspective is the methodological notion of environment as a set of independent variables and organizations as a set of dependent variables. Therefore, we see that

[...] the contingency theory develops two different notions, (1) dependence and (2) uncertainty, side by side. On the one hand contingency means that the structures and practices [...] of a system depend on the way in which the environment becomes relevant to the system, while the reverse situation - the system working on the environment - is not generally taken into consideration [...] (Luhmann, 1976, p. 97).

Thus, contingency is understood as the opposite of necessary. To be contingent implies that there were other possibilities that were not confirmed or "something is contingent insofar as it is neither necessary nor impossible" (Luhmann, 1995, p. 106) and also implies analyzing the relationship between facts since the perspective of the system of environmental variables is recognized in the same way (as independent and therefore as facts).

But as observed above, the relationship between environments and systems is not direct, nor is it based on the flow of information from the environment to the social system. Information is not a suitable concept for the environment, since it is the product of systemic interpretation (Luhmann, 2002). Information, therefore, is always meaningful. The data found in the environment, in order to affect the system in some way, will have to be converted into information since within the context of 
the system what flows is meanings, so that the environment, from the perspective of the system, is constituted as that which is selectively perceived and interpreted by the system (Luhmann, 1995; also Weick, 1969), through a process that is necessarily closed. Likewise, the very notion of environment can only be established form the system as a reference point, so that it becomes coherent to affirm that the environment is (conceptually) a product of the system.

To understand better this possibility, we must resort to the sense attributed to the term meaning, which is the difference between what is real and its several possibilities (Luhmann, 1995, 2002). The meaning of the real depends on its other possibilities, in the perspective of who is defining it. The consequence is that it is real in the environment (as much as in the system) and always provisionally defined, depending on with which of its other possibilities it is being related to. Therefore, the environment is also contingent, also dependent on the system and also subjacent to the risk and possibility of frustration in relation to the system..

Luhmann (1976, p. 105) sums up this circular notion with the term double contingency and proposes a revision of the notion of contingency, suggesting it as a relationship "[...] not between facts, but between contingencies. They may vary on both sides [...]”. for instance, rules in organizations are "[...] designed to govern members' behavior. But the rules are contingent too. They only acquire meaning and positive value through decisions, which implies that they can be altered and may even allow for their alteration [...]" (Luhmann, 1976, p. 99). In these terms, the rule will only be effective when it has meaning and, therefore, acquires some sense for social actors. The implications of this for the institutional theory (and the organizational theory in general) are anticipated partially by Luhmann:

[...] organizational systems themselves react to the difference between them and their environments and base their structural choices on the fact that environmental structures and system structures sometimes vary or can be varied, both dependently and independently of one another. This seems to be the special focus on which organizational systems are differentiated, and the peculiar rationality of their self-organization and management is that they embrace the doubly contingent systemenvironment relationships and carry it further (Luhmann, 1976, p. 108).

\section{Expectation of Expectation or Institutions as an Economy of Consensus}

The third concept to be presented here is related to the notion of double contingency. We must note that if the relationship between system and environment can be contingent in both directions, it becomes better described not as a relationship that originates in any possibility of determination of responses or of behaviors unless only as a relationship based on expectations or as a relationship that always carries a high risk of frustration, does not occur owing to certainties but only of trust. Luhmann states that

One of the most important consequences of double contingency is the emergence of trust or distrust. When entering into situations with double contingency is experienced as particularly risky, they appear. The other can act otherwise than I expected precisely if and because he knows what I expect (Luhmann, 1995, p. 127, italics in original text).

Because of this evident risk (at its limit, paralyzing) the idea that the relationship between system and environment is doubly contingent also becomes coherent to identifying processes by which some degree of trust as to expectations being correct (in both they part of they system and the part of the environment) should emerge and be established. The relationship between system and environment, as a doubly contingent relationship and thus of high risk, implies a relationship between expectations. In short, it is a relationship based on expectations of expectations and not only on expectations of behavior. Therefore,

Under the conditions of double contingency [...] all experimenting and social acting is doubly relevant: one at the level of immediate expectations of behavior, satisfaction or the disappointment 
of that which is expected of another; the other in terms of evaluation of the meaning of behavior itself in relation to the expectation of the other (Luhmann, 1983, p. 48).

For the possibility of a system becoming engaged in social interactions to occur, it is therefore necessary to "[...] have an expectation on the expectation that we have of it" (Luhmann, 1983, p. 48). The very existence of expectations already has a structural value by allowing some security of action (Luhmann, 1995). The reduction of uncertainties, however, originates from the stabilization or generalization of expectations (Luhmann, 1995), which has, in its turn, a double function:

On the one hand, it executes a selection out of the totality of possibilities indicated [...]. And on the other, it bridges discontinuities in fact, temporal, and social regards, so that an expectation can still be used when the situation changes (Luhmann, 1995, p. 97).

In synthesis, the stabilization and generalization of expectations facilitates the selection of alternatives in relation to a complex reality and also brings together discontinuities where the existence of a relationship is not necessarily evident (or where, in fact, it does not indeed exist).

Also according to Luhmann (1983, p. 52), the norm and the Right itself should be understood under this lens, not having any single or main function to make behaviors predictable but rather to make reciprocal expectations compatible $[. .$.$] to regulate the expectation on expectations [\ldots]$ creating $[\ldots]$ security in terms of expectations”. But the norm and the Right can undergo adaptation through mutual understandings concerning behaviors that alter them, modify them or transgress them, therefore depending on their own value. Another social element is included by Luhmann (1989) to analyze this stabilization: the third party (besides those who expect and those who obey or violate a rule, those that have no direct relation with specific social interaction but have expectations concerning it, for instance, the obeying or disobedience of the norm). it is the function of third parties, according to Luhmann (1983, p. 79), to give sustenance to institutions but this occurs indirectly because it is their "supposed opinion that sustains the institution", in a way that whoever acts, acts based on expectations that concern the supposed expectations of third parties, and not in direct response to any imposed obligation, not even only with a base in the supposed expectations of those who interact directly with them.

Institutionalization in this sense is not defined as generalization of consensus but rather as generalization of expectations on the expectation of consensus (or of consensus presumed by third parties).

The function of institutions resides less in the creation and more in the economy of consensus, which is reached as they consensus is anticipated in the expectation on expectations, i.e. as a presupposition, no longer needing, in general, to be concretely expressed (Luhmann, 1983, p. 80).

We thus see a certain double nature of institutions: while referring to third parties, any institution is sustained by normative mechanisms. On the other hand, whether or not to follow these supposed expectations in third parties is still a question of possibility, never a determination. Its existence "[...] does not oblige obedience [...] But it motivates not wanting to face the consequences, not expressing disagreement, structuring thus the chances of communication in the sense of the institution" (Luhmann, 1983, p. 83). In this way, it is evident that there is also a cognitive sustenance mechanism of institutions, which could not be different owing to the operationally closed nature of the social systems and which implies the cognitive structure of meanings (in this case, expectations presumed in third parties are, in short, normative structures processed through meanings and the expectations which are presumed on these expectations are, in their turn, originating from cognitive processes). We may conclude that

This mechanism of institutionalization does not stabilize on its own, [...] but initially stabilized only hypotheses of continuity [...]. In this acceptance, the concept of institution possesses its specific characteristic not in social compulsion, not in the broadening of the concrete consensus and not in the normativity of expectations [...] its function lies in a tangible distribution of positions and behavioral risks, which make likely the maintenance of an experienced social reduction and 
predictably better chances of certain normative projections. Those whose expectations are contrary to those of the institution will have the weight of presumed self-evidence against them (Luhmann, 1983, p. 81).

Therefore, it seems plausible to admit that this mechanism is simultaneously coercive, normative and (mainly) cognitive. The concept of expectation, as well as the two other concepts summarized above, clarifies aspects of the institutional theory and may represent an analytical alternative as we hope to discuss more extensively in the following section of the essay.

\section{NEOFUNCTIONALIST CONTRIBUTIONS TO THE INSTITUTIONAL THEORY OF ORGANIZATIONS}

Neofunctionalism contains different theories as to how to prepare a general theory of social systems. In this sense, it follows the guidance of Münch (1999, p. 201) concerning as "[...] comprehensive paradigm with a set of references in which the postulates of all approaches [analyzed by the author] are preserved" and "capable of including the different institutional fields to which the specific approaches propose to provide suitable explanations". As for the three conflicts in the institutional theory in organizations, with which this essay begun, it appears possible to observe that neofunctionalism suggests alternatives of synthesis between the options of dichotomy.

The notions of systemic openness or closeness, of double contingency and expectations of institutionalized expectations cast a light on the nature of institutions, the institutionalization process and, consequently, organizational processes and structures as processes and structures in institutionalization. As for the first of the conflicts (the relationship between social systems and the institutional environment) it seems possible to admit that, in the neofunctionalist perspective, the system demands institutionalized environmental patterns as a resource to give an initial push to action and those same patterns only acquire a degree of institutionalization as a result of the actions of the results of the implicated systems.

The difference between Luhmann $(1989,1995)$ and Granovetter (1985) seems to lie in the degree in which the relationship with the environment is voluntary (in Granovetter) versus a vision of involuntary autonomy (in Luhmann), in which this relationship occurs as a communication process whenever there are environmental events that 'fire off' the self referring interpretation inherent to the system. The most important difference perhaps is that in keeping with the notion of embeddedness, the meanings are relatively free in that they are freely constructed as the agents interact socially. Meanwhile, in Luhmann, meaning possess a nucleus that belongs to each type of social system, which is synthesized in his theory by the idea of codification. A social system possesses an exclusive binary code around which meaning and interpretation occur of events that lie outside the construction of its environment (see especially Luhmann, 1989). Therefore, in the neofunctionalist theory the process of meaning is not as free as in the sociology of Granovetter, although it is conceived as fully autonomous.

For part of the institutional theory, this notion challenges both the rationalist perspective because it becomes unviable to think of agents voluntarily constructing institutional patterns, with their reference being their interest and as a limit only self interested other agents, and the perspective of institutions as a direct source of motives of action of social agents, be it through normative determinations or cultural-cognitive conditioning. These perspectives focused exclusively on action or social structures are, from a neofunctionalist viewpoint, meaningless (Cohn, 1998): institutions are autonomous products, but not totally voluntary - of social actors (people and systems) implied therein, directly or indirectly, and at the same time they are the resource through which actors are reproduced as psychic systems (people) or social systems. In short, an environmental pattern cannot be analyzed without analyzing the actions that constitute, sustain or alter it as if it were a final, frozen state and independent. Likewise, there is not sense in analyzing actions in an isolated fashion, as if they did not demand stimulus or upsetting and the stabilization provided by environmental patterns. 
For the institutional theory in organizations, one of the main implications of this is that it must definitively abandon the opposition between institutional and strategic analysis of organizations, substituting it with the presupposed idea that in order to understand the actions of organizations, institutions and strategies must be analyzed in their interaction. Institutions only acquire the supposed stability that characterizes them through the ongoing strategic reaction of the actors and social systems affected by them, which takes them as a base of action and strengthens or questions them through the very answers that they stimulated. Likewise, those strategic actions or reactions would not occur without the horizon and the impulse provided by patterns in institutionalization. Institutions and strategies are co-dependent, in a single process, ongoing, always unfinished. According to Münch (1999, p. 204) this relationship refers to the fact that "[...] all concrete action involves a complex fabric of micro-interaction and macro relations, of the sort that both perspectives must compete for analysis". Thus, the joint approach of the two phenomena is not only a theoretical option but indeed a promising alternative for organizational analysis.

The neofunctionalist notions analyzed in this article, especially the idea of double contingency, appear to suggest a more productive analytical focus which falls back on the institutionalization process and not the localization of specific concrete institutions and their impact on actors and social systems because, from the viewpoint of those notions, the supposition that institutions are definitively crystallized is highly unlikely. It would be more productive to take the institutional process in the sense of an ever-growing process in continuous formation and deconstruction, i.e. that always as a concrete side and exterior (on the macro social plane) whose permanence is provisional, be they regulative or normative elements or institutionalized patterns of cognition, exactly because it depends on the relationships carved out in daily life (on the micro-social plane) between actors affected by them and the answers offered by those actors, both in terms of conformity and resistance (Oliver, 1991; Scott, 2001), depending on the meanings attributed to them.

The constructivist notion subjacent to the concept of double contingency suggests that in a neofunctionalist perspective, it would be suitable to characterize the institutional process as referring to the ever ongoing and provisional structuration of institutional patterns and the always autonomous actions of the systems and actions affected by them and constituted as based on patterns in structuration, but always referring to themselves and therefore operationally closed in terms of internal meanings to the systems themselves.

This model reminds one of a continuous spiral of the frontiers between system and environment and which is developed as they system is self constructed through conformity or differentiation (in organizations through their strategic responses) in relation to environmental aspects to which the system itself provides a meaning. In this sense ${ }^{(2)}$, an institution is never the [...] outcome or end state of an institutionalization process" (Tolbert \& Zucker, 1996, p. 204) but always a temporary state and, in conceptual terms, an artifice used to measure process which is indeed continuous. Thus, this empirical analysis would require going beyond the formal or explicit aspects of institutional elements also to analyze necessarily the aspects of daily life of the strategic reactions that suggest in answer to those elements and which, at the same time, (re)constitutes them.

These systemic notions also cast a doubt on the regulating or controlling role of institutions, suggesting that even high degrees of institutionalization would not mean automatic responses, be it on the normative or cognitive plane and, mainly, if the reference is to social regulative patterns, imposed coercively. As seen above, the function of institutions does not lie in the control of behavior but rather in the increase in trust, which occurs when expectations are stabilized as to the supposed expectations of third parties. This stabilization offers a clearer horizon and makes it more likely (not more than this) that there will be certain types of responses.

We must not expect a social rule to be born with the stability that characterizes institutional patterns. These patterns, as pointed out by Scott $(1994,1995,2001)$, are institutional elements, but do not in themselves constitute institutions. In a neofunctionalist sense, the institutional process should be understood as including two aspects. The first would correspond to which social elements are being institutionalized. For instance, which aspects of a new law or government policy, or even an 
organizational plane are receiving what type of responses from agents and systems they are aimed at and which they should supposedly regulate. The second would correspond to the social plane in which it acquires stability: as seen above, the idea of institutionalization here implies both expectations on the macro-social plane and expectations of expectations on the micro-social plane. A law ay exist and never affect in any way the behavior of some systems and social agents, or may affect them differently from what could initially have been contained in the text of the law as an expectation and thanks to the institutionalization process itself, the same happening with values, beliefs or socially generalized typifications.

From this perspective, the critique of Tolbert and Zucker (1998) of Meyer and Rowan (1977) concerning the possibility of unconnected actions in relation to highly institutionalized patterns only makes sense when we think of institutions as social facts that may reach such a high grade of stabilization to the point that they become objectified, determining behaviors and meanings. If institutions are though of as an ongoing process, as possibility or as stabilization of the hypothesis of their continuity through generalized expectations (Luhmann, 1983), then that degree of determination as being of the institutional phenomenon must not be admitted. In the neofunctionalist theory, institutions cease to be understood as containing consensus de facto. They only imply the expectation of consensus and thus their stabilization and continuity are always provisional and their impact on actions is never of an exclusive nature because even when coercive imposition occurs, its interpretation of the cognitive environment and its stabilization on the normative plane also has to occur. As such, they may suffer resistance (explicit or veiled) at any moment as long as there are social actors willing to assume the presumed risks of this behavior and own up to the responsibility of destabilization of the parameters supposed tacitly or accepted expressly (Luhmann, 1983).

Thus, a loose coupling is always expected in relation to any institutionalization parameter since the action is the product of its interpretation by the system. For this same reason, a point-to-point correlation is what is least expected in relation to any type of institutional pattern (according to Luhmann, 1989; Meyer \& Rowan, 1977 and also Weick, 1969), and its complete rejection is even less expected. Its complete rejection is highly unlikely and becomes more difficult the more the institutional pattern is socially stabilized. The degree of correlation, in short, will depend mainly on the internal logic of the implicated systems themselves (Machado-da-Silva \& Fonseca, 1999; Meyer \& Rowan, 1977; Selznick, 1996), because of perceptive and interpretative interests and patterns (Scott, 2001) which lead them to harness to those institutional patterns meanings which may lead or not to their pretensions of technical efficiency, leadership or simply obtaining social legitimacy, among others.

We may conclude that in this perspective, the correlation between organizational structures and actions and institutional forces is circular: the structures and actions are guided by environmental forces. On the other hand, these environmental forces enter the institutionalization process when there is a certain degree of correlation, i.e. when they are responded to positively.

When an institution is understood not as a final state but rather as a provisional stabilization of expectations of consensus, it becomes easier to understand why they do not determine action. If the actions of the systems are based on expectations (micro-social plane) of expectations presumed in third parties (macro-social plane), then as these expectations of third parties are institutionalized at a high degree, the greater the possibility there will be of expectations being developed that are coherent with them. Thus it is that institutions affect action, without determining it. This mechanism helps us to understand how reproduction of social patterns and actions can be thought of without having to succumb to the idea of environmental determination of actions as here we are dealing more with increased normative and cognitive safety than the expectations presumed in the direct reproduction of social patterns or externally dictated behaviors. Furthermore, the consequence of institutions is more to provide that type of stability of expectations than to dictate homogenous patterns which are much more fiction than fact (Luhmann, 1983). 
This ecology of institutions could then be resumed in the logic by which social patterns of a regulative, normative and cognitive nature are considered as supported by the general opinion, by third parties and, therefore, acquire social force by being presumed consensual.

The institutional notion proposed here includes the fact that any of the institutional elements (according to Scott, 1995) acquires some degree of relevance and capacity to affect social systems exactly because - and as - they are perceived and interpreted by those systems. Through perception and interpretation of the institutional elements, they come to have some meaning from the viewpoint of the systems, becoming more or less relevant especially because of the meaning attributed to them and the actions and reactions that the systems elaborate as responses to them, these meanings being constructed based on the expectation of consensus presumed by third parties. Therefore, institutions are social phenomena that are temporarily stable and always subject to the process of social construction.

\section{FINAL CONSIDERATIONS}

What we are attempting to propose here is not a breaking with explanations given for the institutionalization of organizational characteristics. By examining neofunctionalist and institutionalist explanations, it does not mean a wish to formalize a new institutional theory but rather to show the possibilities for understanding phenomena that are still under analysis in the context of the theory of organizations, mainly the explanation of the institutionalization process as a process that involves simultaneous levels of occurrence. These aspects are already found in the institutional analysis done by authors and researchers in other theoretical fields and by some authors within the field of organizations, but it seems that this is not yet the predominant line in organizational studies, which has implied obsolescence of the field in some of the analyses or, in other cases, become superfluous because of the criticisms leveled against it.

Also, by focusing simultaneously on the cognitive and normative nature of institutional patterns, neofunctionalist theory seems to indicate ways to overcome the dichotomy marked by objectivist positions of the understanding of organizational reality (when these organizations, and also institutions, are understood as concrete facts and absolutely external to individual consciences) versus positions that are supported exclusively in the subjective nature of the organizational and institutional phenomenon and deny them any supra-individual element. It is understood here that in the neofunctionalist conception, the institutional phenomenon includes a normative dimension and, therefore, at least inter-subjective, because the expectations and values always emerge from interaction of social agents, and also a cognitive dimension because these same expectations and values are primarily perceived and interpreted so that answers can be generated.

On the other hand, the desire here is not to suggest that the neofunctionalist theory includes all the analytical possibilities implied in the institutional perspective. It is constituted as another possible form of study of the institutionalization process, with implications, possibilities and specific limitations, but certainly not the only possible perspective. The complex and multi-paradigmatic nature of the neofunctionalist approach, however, casts lights on the recursive logic of the institutionalization process, which seems to be in tune with tendencies of social theory and theoretical and paradigmatic advances already seen in other areas of human and social knowledge for a long time and in relation to which the theory of organizations seems to be lacking in being up to date.

In short, what is expected is that this analytical line, i.e. the approach of the institutionalization process through the Luhmannian theory of neofunctionalism, should contribute to the already present effort to re-explain the organizational and social phenomena, adding new explicative horizons to the perspectives that are already traditional and, as is inevitable, new limitations. 


\section{ACKNOWLEDGEMENTS}

This paper was prepared with the support of CAPES, an organ of the Brazilian Government for the qualification of human resources.

\section{NOTES}

\footnotetext{
${ }^{1}$ This paper received the ANPAD AWARD as the best paper presented at XXIX ANPAD Conference (Brasília, Brazil) in 2005.

2 The term institutionalizing is suggested to Express the processual sense implied in this description similar to that of Machado-da-Silva, Fonseca and Crubellate (2005) and following the notion of organizing, proposed by Weick (1969).
}

\section{REFERENCES}

Barley, S., \& Tolbert, P. (1997). Institutionalization and structuration: studying the links between action and institution. Organization Studies, 18(1), 93-117.

Bednarz, J., Jr. (1989). Translator's introduction. In N. Luhmann (Coord.). Ecological communication (pp vii-xvi). Chicago: The University of Chicago Press.

Bertalanffy, L. (1975). Teoria geral dos sistemas (2a ed.). Petrópolis: Vozes.

Boudon, R. (1998). Limitations of rational choice theory. American Journal of Sociology, 104(3), 817828.

Cohn, G. (1998). As diferenças finas: de Simmel a Luhmann. Revista Brasileira de Ciências Sociais, 13(38), 53-62.

DiMaggio, P., \& Powell, W. (1983). The iron cage revisited: institutional isomorphism and collective rationality in organizational fields. American Sociological Review, 48(2), 147-160.

DiMaggio, P., \& Powell, W. (1991). Introduction. In W. Powell \& P. DiMaggio (Eds.). The new institutionalism in organizational analysis (pp. 1-38). Chicago: The University of Chicago Press.

Granovetter, M. (1985). Economic action and social structure: the problem of embeddedness. American Journal of Sociology, 91(3), 481-510.

Katz, D., \& Kahn, R. (1976). Psicologia social das organizações. São Paulo: Atlas.

Lourau, R. (1995). A análise institucional. Petrópolis: Vozes.

Luhmann, N. (1983). Sociologia do direito I. Rio de Janeiro: Tempo Brasileiro.

Luhmann, N. (1976). A general theory of organized social systems. In G. Hofstede \& S. Kassem (Eds.). European contributions to organization theory (pp. 96-113). Amsterdam: Van Gorcum.

Luhmann, N. (1989). Ecological communication. Chicago: The University of Chicago Press.

Luhmann, N. (1995). Social systems. Stanford: Stanford University Press.

Luhmann, N. (2002). Theories of distinction. Stanford: Stanford University Press. 
Machado-da-Silva, C. L., \& Fonseca, V. (1999). Competitividade organizacional: conciliando padrões concorrenciais e padrões institucionais. In M. Vieira \& L. Oliveira (Eds.). Administração contemporânea: perspectivas estratégicas (pp. 27-39). São Paulo: Atlas.

Machado-da-Silva, C. L., Fonseca, V., \& Crubellate, J. (2005). Estrutura, agência e interpretação: elementos para uma abordagem recursiva do processo de institucionalização. Revista de Administração Contemporânea, 9(1ª Edição Especial), 9-40.

Maturana, H. (2002). Prefácio de Humberto Maturana Romesin à $2^{\mathrm{a}}$ edição. In H. Maturana \& F. Varela (Coords.). De máquinas e seres vivos (2a ed.). Porto Alegre: Artmed.

Meyer, J., \& Rowan, B. (1977). Institutionalized organizations: formal structure as myth and ceremony. American Journal of Sociology, 83(2), 340-363.

Münch, R. (1999). A teoria parsoniana hoje: a busca de uma nova síntese. In A. Giddens \& J. Turner (Eds.). Teoria social hoje (pp. 175-228). São Paulo: Editora UNESP.

Oliver, C. (1991). Strategic responses to institutional processes. Academy of Management Review, 16(1), 145-179.

Parsons, T. (1951). The social system. New York: Free Press.

Paterson, J. (1997). An introduction to Luhmann. Theory, Culture \& Society, 14(1), 37-39.

Ranson, S., Hinings, B., \& Greenwood, R. (1980). The structuring of organizational structures. Administrative Science Quarterly, 25(1), 1-17.

Scott, W. R. (1994). Institution and organizations: toward a theoretical synthesis. In W. R. Scott \& J. Meyer (Eds.). Institutional environments and organizations: structural complexity and individualism (pp. 55-80). Thousand Oaks: SAGE.

Scott, W. R. (1995). Introduction: institutional theory and organizations. In W. R. Scott \& S. Christensen (Eds.). The institutional construction of organizations (pp. xi-xxiii). Thousand Oaks: SAGE Publications.

Scott, W. R. (2001). Institutions and organizations (2nd ed.). Thousand Oaks: SAGE.

Scott, W. R., \& Meyer, J. (1994). Institutional analysis: variance and process theory approaches. In W. R. Scott \& J. Meyer (Eds.). Institutional environments and organizations: structural complexity and individualism (pp. 81-112). Thousand Oaks: SAGE.

Selznick, P. (1957). Leadership in administration. New York: Row, Peterson and Co.

Selznick, P. (1966). TVA and the grass roots. New York, Harper \& Row.

Selznick, P. (1996, June). Institutionalism “old” and “new”. Administrative Science Quarterly, 41, pp. 270-277.

Simon, H. (1970). Comportamento administrativo (2a ed.). Rio de Janeiro: FGV.

Tolbert, P., \& Zucker, L. (1983). Institutional sources of change in the formal structure of organizations: the diffusion of civil service reform, 1880-1935. Administrative Science Quarterly, 28(1), 22-39.

Tolbert, P., \& Zucker, L. (1996). The institutionalization of institutional theory. In S. Clegg, C. Hardy, \& W. Nord (Eds.). Handbook of Organization Studies (pp.175-190). London: SAGE.

Weick, K. (1969). The psychology of organizing. Reading: Addison-Wesley Publ. Co.

Westphal, J., \& Zajac, E. (2001). Decoupling policy from practice: the case of stock repurchase programs. Administrative Science Quarterly, 46(2), 202-228. 
Zucker, L. (1991). The role of institutionalization in cultural persistence. In W. Powell \& P. DiMaggio (Eds.). The new institutionalism in organizational analysis (pp. 83-107). Chicago: The University of Chicago Press. 